\section{THOUGHTS ON THE HIGHER EDUCATION OF WOMEN*}

THERE are certain confusions of ideas as to the proper range and extent of the education of women, with other and vastly different questions as to the right of the softer sex to enter upon certain kinds of professional training. Let us endeavour to get rid of some of these misconceptions. In the first place, no one clenies the right to an equality of the sexes in all the elementary education given in ordinary schools. This is admitted to be an essential preparation in the case of all persons of both sexes and of all grades of social pesition for the ordinary work of life. But, when we leare the threshold of the common school, a divergence of opinion and practice at once manifests itself. Only a certain limited proportion either of men or women can go on to a hirher education, and those who are thus selected are either those who by weal: $h$ and social position are enabled or obliged to do so, or those who intend to enter into professions which are believed to demand a larger amount of learning. The question of the higher education of women in any country depends very much on the relative numbers of these classes among men ard women, and the views which may be generally held as to the importance of education for ordinary life, as contrasted with professional life. Now in Canada the number of young mea who receive a higher education merely to fit them for occupying a high social position is very small. The greater number of the young men who pass through our colleges do so under the compulsion of a necessity to fit themselves for certain professions. On the other hand, with the exception of those young women who receive an education for the profession of teaching, the great majority of those who obtain what is regarded as higher culture, do so merely as a means of general improvement and to fit themselves better to take their proper place in society. Certain curious and important consequences flow from this. An education ob. tained for practical professional purposes is likely to partake of this character in its nature, and to run in the direction rather of hard utility than of ornament. An education obtained'as a means of rendering its possessor agreeable is likely to he astletical in its character ratber than practical or useful. An education pursued as a means of bread-winning is likely to be sought by the active and ambitious of very various social grades. An educa:ion which is thought merely to fit for a certain social position is likely to be sought almost exclusively by those who move in that position. An education intended for recognised practical uses, is likely to find public support, and at the utmost to bear a fair market price. An educa tion supposed to have a merely conventional value as a branch of refined culture, is likely to be at a fancy price. Hence it happens that the young men who receive a higher education and by means of this attain to positions of respectability and eminence, are largely drawn from the humbler strata in society, while the young women of those social levels rarely aspire to similar advantages. On the other hand, while numbers of young men of wealthy families are sent into business with a merely commercial education at a very early age, their sisters are occupied with the pursuit of accomplishmen:s of which their more practical brothers never dream. When to all this is added the frequency and rapidity in this country of changes in social standing, it is easy to see that an educational chaos must resuli, most amusing to any ore who can philosophically contemplate it as an outsider, but most bewildering to all who have any practical concern with it; and more especially, I should suppose, to careful and thoughtful mothers, whose minds are occupied with the connections which their daughters may form, and the positions which they may fill in society. The educational problem which these facts present admits, I believe, of but two general solutions. If we could involve women in the same necessities for independent exertion and professional work with men, I have no doubt that in the struggle for existence they would secure to themselves an equal, perhaps greater, share of the more solid kinds of the higher education. Some strong-minded women and chivalrous men in our day favour this solution, which has, it must be confessed, more show of reason in older countries where, from unhealthy social conditions, great numbers of unmarried women have to contend for their own subsistence. But it is opposed by all the healthier instincts of our humanity. A better solution would be to separate in the case of both sexes professional from general education, and to secure a large amount of the former of a

Extracted from the Introductory Lecture to the First Session of the Classes of the Ladies' Educational Association of Montreal, October, x87x, solid and practical character for both sexes, for its own sake, and because of its beneficial results in the promotion of our well-being considered as individuals, as well as in ourfamily, social and professional relations. This solution also has its difficulties, and it can, I fear, never be fully worked out, until either a higher. intellectual and moral tone be reached in society, or until nations visit with proper penalicies the failure, on the part of those who have the means, to give to their children the highest at tainable education, and with this also provide the means for educating all those who, in the lower schools, prove themselves to be possessed of eminent abilities. It may be long before such laws can be instituted, even in the more educated communities; and in the meantime in aid of that higher appreciation of the benefits of education which may supply a better if necessarily less effectual stimulus, I desire to direct your attertion to a $f \in W$ considerations which show that young women, viewed not as future lawyers, physicians, politicians, or even teachers, but as future wives and mothers, should enjoy a bigh and liberal culture, and which may help us to understand the nature and means of such culrure.

It is in the maternal relation that the importance of the education of wornan appears most clearly. It requires no very extensive study of biography to learn that it is of less conse. quence to any one what sort of father he may have had than what sort of mother. It is indeed a popular impression that the children of clever fathers are likely to exhibit the opposite quality. This I do not believe, except in so far as it results from the fact that men in-public positions or immersed in business are apt to neglect the oversight of their children. But it is a noteworthy fact that eminent qualities in men may almost always be traced to similar qualities in their mothers. Knowledge, it is true, is not hereditary, but training and culture and high mental quali. ties are so, and [ belicve that the transmission is chiefly through the mother's side. Further, it is often to the girls rather than to the boys, and it frequently happens that if a selection were to be made as to the members of a family most deserving of an elaborate and costly education, the young women would be chosen rather than the young men. But leaving this physiological view, let us look at the purely educational. Imagine an educated m:ther, training and moulding the powers of her children, giving to them in the years of infancy those gentle yet permanent ten. dencies which are of more account in the formation of character than any subsequent educational influences, selecting for them the best instructirs, encouraging and aiding them in their difficulties, sympa hising with them in their successes, able to take an intelligent interest in their progress in literature and science. How ennubling such an influence, how fruitful of good resuits, how certain to secure the warm and lasting gratitude of those who have received its henefits, when they look back in future life on the paths of wisdom along which they have been led. What a contrast to this is the position of an untaught motherfinding her few superficial accomplishments of no account in the work of life, unable wisely to guide the rapidly-developing mental life of her children, bringing them up to repeat her own failures and errors, or perhaps to despise her as ignorant of what they must learn. Truly the art and profession of a mother is the noblest and most far-reaching of all, and she who would worthily diccharge its dulies must be content with no mean preparation It is perhaps worth while also to say here that these duties and responsibiliries in the future are not to be measured altogether by those of the past. The young ladies of to-day will have greater demands made on their knowledge than those which were made on their predecessors.

But the question has still other aspects. A woman may be destined to dwell apart-to see the guides and friends of youth disappearing one by one, or entering on new relations that sepa. rate them from her, and with this isolation may come the hard necessity to earn bread. How many thus situated must sink into an unhappy and unloved dependence? How much better to be able to take some useful place in the world, and to gain an honourable subsistence ! But to do so, there must be a foundation of early culture, and this of a sound and serviceable kind. Or take another picture. Imagine a woman possessing abund. ance of this world's goods, and free from engrossing cares. If idle and ignorant, she must either retire into an unworthy insignificance, or must expose herself to be the derision of the shrewd and clever and the companion of fools. Periaps, worse than this, she may be a mere leader in thoughtless gaiety, a snare and a trap to the unwary, a leader of unsuspicious youth into the ways of dissipation. On the other hand, she may aspire to be a wise steward of the goods bestowed on her, a centre of influence, aid, and counsel in every good work, a shelter and support to the 
falling and despairing, a helper and encourager of the useful and active; and she may be all this and more in a manner which no man, however able or gifted, can fully or effectually imitate. But to secure such fruits as these, she must have sown abundantly the good seed of mental and moral discipline in the sunny spring time of youth. Lastly, with reference to this branch of the subject, it may be maintained that liberal culture will fit a woman better even for the ordinary toils and responsibilities of househrld life. Even a domestic servant is of more value to her employer if sufficiently intelligent to understand the use and meaning of her work, to observe and reason about the best mode of arranging and managing it, to be thoughtful and careful with reference to the things committed to her charge. How much more does this apply to the head of the house, who, in the daily provisioning and clothing of her little household army, the care of their health, comfort, occupations and amusements, the due and orderly subordination of he duties and interests of servants, children, and friends, and the arrangement of the thousand difficulties and interferences that occur in these relarions, has surely much need of sys em, tact, information, and clearness of thought. We realise the demands of her position only when we consider that she has to deal with all interests from the commonest to the highest, with all classes of minds from the youngest and most untutored to the most cultivated; and that she may be required at a moment's notice to divert her thoughts from the gravest and most serious concerns to the most trifing details, or to emerge from the practical performance of the most commonplace duties into the atmosphere of refined and cultivated society. But it would be altogether unfarr to omit the consideration of still another aspect of this matter. Woman bas surely the right to be happy as well as useful, and should have fully opened to her that exalted pleasure which arises from the development of the mind, from the exploration of new regions of thought, and from an enlarged acquaintance with the works and ways of God. The man who has enjoyed the gratification of exercising his mental powers in the fields of scientific investigation or literary study - of gathering their flowers and igems, and of breathing their pure and bracing atmosphere, would surely not close the avenues to such high enjoyment against woman. The desire to do so would be an evidence of sherr pedantry or moral obliquity, of which any man should be ashamed. On the contrary, every educated man and woman should in this respect be an educational mis onary, most de sirous that others should enjoy these pleasure; and privileges, both as a means of happiness and as a most effectual preventive of low and pernicious tastes and pursuits.

\section{RECENT RESEARCHES ON FLIGHT*}

$\mathrm{O} F$ late the perplexing problem of flisht has received a greater amount of attention from physiologists and savants than has been bestuwed upon it for years, an i the result of their researches and experiences is in a fair way of becoming rem rk able for its fruit-bearing characier. Whilst abruad, such men as Borelli, Straus-Durckheim, Chabrier, Girard, and Marey, have severally given to the world the gist of their labours in this branch of science; at home, the Duke of Argyll and Dr. J Bell Pettigrew have awakened our deep interest by their views on natural and artificial fight. To the latter is clue the honour of giving birth to the celebrated "figure-of-8 wave theory," that is now attracting so much notice in o:ur aeronautical schiouls.

As early as I 867 , Dr. Pettigrew delivered, hefore the Royal Institution of Greal Briain, a lecture, in which he propoun:ed that novel the:ry, and in 1868 "e published in the "Transactions" of the Linnean Suciety an elaborate men:oir on "The Mechanical Apphances by which Flight is attained in the Animal Kingdom." The year after, Prof. J. E. Marey, in the "Revue des Cours Scientifiaues," bore out Dr. Pettigrew's ideas, by the detail of his experiments wirh the sphygmograph, with which he succeeded in causing the wings of insects and birds to register their own movements. He says :- "But if the frequency of the movements of the wing vary, the form does not vary. I is invariably the same; it is always a double loop, a figure of 8 Whecher this figure be more or less apparent, whether its branches be more or less equal, matters little : it exists, and an attentive examination will not fail to reveal it." An indefatigable worker, Dr. Pettigrew continued, without pausing, the task to which he had set himself-and that to him is indeed a labour of love ; and in this year's "Transactions" of the Royal Society of Edinburgh, we have from his pen a complete monograph on "The Physiology of Wings," in which he treats with equal felicity of both natural and artificial flight. The mass of interesting fact brought to light by the author is too copious to allow of lengthened discussion, but from it we abstract the following items :-..

"The wing is generally triangular in form. It is finely graduated, and tapers from the root towards the tip. It is likewise slightly twisted upon itself, and this remark holds true also of the primary or rowing feathers of the wing of the bird. The wing is convex above and concave below; this shape, and the fact that in flight the wing is carried obliquely forward like a kite, enabling it to penetrate the air with its dorsal surface during the up stroke, and to seize it with its ventral one alike during the down and up strokes. The wing is moveable in all its parts; it is also elastic. Its power of changing form enables it to be wielded intelligently, even to its extremity ; its elasticity prevents shock, and contributes to its continued play. The wing of the insect is usually in one piece, that of the bat and bird always in several. The curtain of the wing is continuous in the bat, because of a delicate elastic membrane which extends between the fingers of the hand and along the arm; that of the bird is non-continuous, owing to the presence of feathers, which open and close like so many valves during the up and down strokes.

"The posterior margin of the wing of the insect, bat, and bird, is rotated downwards and forwards during extension, and upwards and backwards cluring flexion. The wing during its vibration descends further below the body than it rises above it. This is necessary for elevating purposes. The distal portion of the wing is twisted in a downward and forward direction at the end of the down stroke, whereas at the end of the up stroke it is twisted downwards and backwards. The wing during its vitrations twists and untwists, so that it acts as a reversing reciprocating screw. The wing is consequently a screw, structurally and functionally. The blur or impression produced on the eye by the rapidly oscillating wing is twist-d upon itseli, and resemtles the blade of an urdinary screw-propeller. The twisted conliguration of the wing and is screwing action are due to the presence of figure-of 8 loinped curves on its anterior and posterior margins; the curves, when the wing is vibratıng, reversing and reciprocating in such a manner as to make the wing change form in all its part.."

We may further point out that Dr. Peitigrew has not based his ideas on the structure of wings on mere theoretical censidera. tions. Besides elaborate anat omical examination, he has entered with a true experimenral spirit into a close study of the visible movements of most of the winged tribe. The very excellent diagramatic vitws with which his paper is elabora ely illustrated convey at a glance much that it is difficult to express in words. In proof of th:s the reader need but compare those figures bearing $n \%$ the wing movements of the butterfly, the dragon-fly, and the third.

On these and similar deductions from the practical study of natural history, Dr. Pettigrew bases his element; of artificial fight.

J. MURIE

\section{INSTRUCTIONS FOR OBSERVERS, AT THE ENGLSH GOVERNMENT ECLIPSE EXPE- $D I T Y N, 1871$}

\section{SPEC I ROSCOPIC OBSERVATIONS}

THE instruments used should, if possible, be of the following form:s; and experience has suoun that they should all be equatorially mounted and driven by clockwork ( $\mathbb{E}$ of course excepte, i) :-

Instrument $A$. - An analysing spectroscope showing the whole spectrum in one field, with reference spectra, or some means of rapid record, and with long slit and long collimator mounted at right angles to the axis of a reflecting telescope of large aperture and short focal length, with la.ge finder, the slit of the spectroscope, of course, lying in the facus of the speculum. This combination enables us to obtain a small bright image of the corona, and by throwing this small image on the long slit, to observe the spectrum of the corona on both sides the dark moon-the long collimator permitting the slit to be as wide as possible, so that the maximum of light is admitted. The prism throwing the reference-spectrum into the collimator slides along a bar, so that the reference-spectrum may be made to occupy any part of the 